\title{
RISK FACTORS OF ARTERIAL HYPOTENSION AFTER INTRADURAL SPINAL ANESTHESIA IN CESAREAN
}

GIL BONA J., PEÑA CALVO P., ROVIRA FLORES E., BORQUE MARTÍN JL., ORTEGA LUCEA S., MUÑOZ RODRÍGUEZ L., DEPARTMENT OF ANESTHESIOLOGY. MIGUEL SERVET HOSPITAL. ZARAGOZA.

\section{OBJECTIVE}

To assess the risk factors for arterial hypotension after intradural anesthesia in elective cesarean

\section{MATERIAL AND METHOD}

We performed a prospective study including elective caesarean performed at the obstetrics service of the Miguel Servet University Hospital from November 2012 to March 2015. We exclude the non-acceptance of participation in the study, the presence of uterine dynamics or the suspicion of maternal-fetal pathology

All patients underwent an intradural anesthesia with $0.5 \%$ hyperbaric bupivacaine and doses according to the size (<155cms-10mg, 155-165-11mg, $>165-12 \mathrm{mg}$

Basal Systolic blood pressure (SBP) was defined as an average of three consecutive measures with the patient at rest and in the lateral decubitus preferred. Control pressures were taken with a left tilt of $15^{\circ}$

Hypotension was defined as any decrease in SBP below $80 \%$ of baseline SBP, as well as declines that did not reach $20 \%$ but were accompanied by symptoms of cerebral hypoperfusion (dizziness and / or nausea)

We made a comparative analysis evaluating data according patients had or not arterial hypotension after intradural anesthesia.

To correlate different variables we used the chi square of Pearson or Fisher test for discrete variables and t-student or $U$ Mann-Whitney test for continuous variables. Significance at $\mathrm{p}<0.05$

To calculate the odds ratio for each of the risk factors we applied a multivariate binary logistic regression model with confidence interval of $95 \%$

\section{RESULTS}

\begin{tabular}{|l|l|l|l|}
\hline DATA & NoArterial Hypotension & Arterial Hypotension & P= \\
\hline Number & 19 & 33 & $0.02^{\mathrm{a}}$ \\
Age (years) & $32.0(4.5)$ & $35.3(4.7)$ & $0.156^{\mathrm{a}}$ \\
Size $(\mathrm{cm})$ & $164.3(6.5)$ & $161.8(5.9)$ & $0.089^{\mathrm{a}}$ \\
Weight $(\mathrm{Kg})$ & $69.4(7.1)$ & $73.7(10.5)$ & $0.042^{\mathrm{a}}$ \\
BMl(Kg/m2) & $25.8(3.5)$ & $28.2(4.1)$ & $0.009^{\mathrm{b}}$ \\
Gestational age(weeks) & $39.0(38.0-39.0)$ & $38.0(37.0-39.0)$ & $0.368^{\mathrm{b}}$ \\
Anesthesia time (min) & $15.0(12.0-16.0)$ & $16.0(11.5-20.0)$ & $0.488^{\mathrm{b}}$ \\
Fetal extraction time(sec) & $75.0(40.0-100)$ & $70.0(55.0-105)$ & $0.977^{\mathrm{b}}$ \\
Baseline SBP & $98.0(92.0-106)$ & $99.0(92.0-108.0)$ & $0.725^{\mathrm{b}}$ \\
Baseline HR & $81.0(75.0-86.0)$ & $82.0(74.0-90.0)$ & $0.490^{\mathrm{b}}$ \\
Variation SBP (DL-SD) ${ }^{*}$ & $9.5(4.0-16.25)$ & $9.0(2.5-12.5)$ & $0.021^{\mathrm{b}}$ \\
Variation HR (LD-SD) & & \\
\hline
\end{tabular}

a- Values expressed as means (+/- typical deviation) and compared using the Student's T-test

b- Values expressed as medians (interquartile range) and compared using the U-Mann-Whitney test

*Change from lateral decubitus to supine

Results of the multivariate binary logistic regression model for risk of hypotension
\begin{tabular}{|l|l|l|l|}
\hline Data & coefficient & Odds Ratio (95\% Cl) & P= \\
\hline Age (Years) & 0.230 & $1.26(1.04-1.56)$ & 0.02 \\
\hline BMl(Kg/m2) & 0.236 & $1.27(1.01-1.58)$ & 0.036 \\
\hline Gestational age(weeks) & -1.194 & $0.3(0.12-0.79)$ & 0.014 \\
\hline Variation HR(LD-SD)bpm & 0.175 & $1.19(1.03-1.38)$ & 0.019 \\
\hline
\end{tabular}

\section{CONCLUSIONS}

Maternal age, body mass index, gestational age, and change in heart rate when the patient moved from the lateral decubitus to the supine position are confirmed as independent predictors of the risk of hypotension following intradural spinal anesthesia in cesarean. 